\title{
TRUE AND APPARENT PALEONTOLOGIC PATTERNS PRODUCED BY STRATIGRAPHIC SEQUENCES
}

\author{
HOLLAND, Steven M., Geology Department, University of Georgia, Athens, GA \\ 30602, U.S.A.
}

The widespread occurrence of stratigraphic sequences suggests that a large fraction of the stratigraphic record is systematically biased. For example, sequences in landward areas tend to have more symmetrical transgressive-regressive records as well as hiatuses of long duration. Sequences in shelf settings have highly asymmetrical regressivedominated records, with relatively minor hiatuses and condensed sections. Deeper settings tend to have more symmetrical transgressive-regressive records, with significant condensed sections. This stratigraphic bias can both mask true paleontological patterns and create apparent patterns.

Sequence architecture implies that environments are continually changing, whether this change is obvious in lithofacies or not. Given that facies control has been documented in many benthic taxa as well as in planktic/nektic/nektobenthic groups that are biostratigraphically important (e.g., conodonts, ammonoids, and graptolites) continuous change in lithofacies suggests that faunas should continually change upsection--and that this change should reflect changing environments, not in situ evolution. Vertical changes in taxonomic composition and morphology are more easily explained as clines or ecophenotypic gradients, rather than as evolutionary sequences. Because stratigraphic sequences cause vertical facies successions to be repeated, fossil morphologies should repeatedly appear within a section, with their occurrences separated by a hierarchy of gaps, varying in scale from short-term taphonomic-bias gaps through parasequence-scale gaps to sequence-scale gaps. Morphotypes with stratigraphically discontinuous ranges commonly have been named separately despite the morphological similarity at different horizons, and in some cases, this pattern has been interpreted as iterative evolution. However, sequence architecture and facies control could easily produce this pattern. It is argued here that the Lazarus Effect of Jablonski is far more pervasive than previously acknowledged and can occur at a range of scales from a variety of processes.

The juxtaposition of dissimilar facies at sequence boundaries can produce apparent paleontological events, while facies control will mask true paleontological events. Apparent first occurrences will be concentrated immediately above sharp facies contacts at sequence boundaries, whereas apparent last occurrences will be concentrated immediately below sequence boundaries. However, a true first occurrence within a section will inevitably be delayed from the true first occurrence within the basin because of facies control; likewise, true last occurrences within a section will precede the true last occurrence within a basin. The magnitude of this delay/precedence will vary with the position of the section within the basin. The asymmetric sequences of midshelf settings can cause a delay of up to one full sequence; more symmetrical sequences of landward and basinward settings can create a of up to approximately one-half of a sequence.

What can be done about this source of bias? One solution is to create a tight eventstratigraphic correlation network in conjunction with a basin-wide array of sections to be able to track any given facies through time and space. A second solution, useful where such correlations are not possible or such an array of sections is not available, would be to compare within-habitat faunal and morphologic change between sequences.

Possibly the most intriguing possibility is that the same processes that create stratigraphic sequences also drive macroevolutionary change through geologically rapid reassortment of sedimentary environments and the redistribution of barriers to isolation. 